\title{
Saharan dust events at the Jungfraujoch: detection by wavelength dependence of the single scattering albedo and first climatology analysis
}

\author{
M. Collaud Coen ${ }^{1}$, E. Weingartner ${ }^{2}$, D. Schaub ${ }^{3}$, C. Hueglin ${ }^{3}$, C. Corrigan $^{2,4}$, S. Henning ${ }^{2,5}$, M. Schwikowski ${ }^{6}$, and \\ U. Baltensperger ${ }^{2}$ \\ ${ }^{1}$ MeteoSwiss, Aerological Station, Les Invuardes, CH-1530 Payerne, Switzerland \\ ${ }^{2}$ Laboratory of Atmospheric Chemistry, Paul Scherrer Institut, CH-5232 Villigen PSI, Switzerland \\ ${ }^{3}$ Swiss Federal Laboratories for Materials Testing and Research, Überlandstrasse 129, CH-8600 Dübendorf, Switzerland \\ ${ }^{4}$ University of California, San Diego, 9500 Gilman Drive, MC 0221, La Jolla, CA 92093-0221, USA \\ ${ }^{5}$ Chemical Institute, Copenhagen University, DK-2100 Copenhagen, Denmark \\ ${ }^{6}$ Laboratory of Radio- and Environmental Chemistry, Paul Scherrer Institut, CH-5232 Villigen PSI, Switzerland
}

Received: 25 September 2003 - Published in Atmos. Chem. Phys. Discuss.: 10 November 2003

Revised: 4 June 2004 - Accepted: 4 December 2004 - Published: 8 December 2004

\begin{abstract}
Scattering and absorption coefficients have been measured continuously at several wavelengths since March 2001 at the high altitude site Jungfraujoch (3580 m a.s.1.). From these data, the wavelength dependences of the Ångström exponent and particularly of the single scattering albedo are determined. While the exponent of the single scattering albedo usually increases with wavelength, it decreases with wavelength during Saharan dust events (SDE) due to the greater size of the mineral aerosol particles and their different chemical composition. This change in the sign of the single scattering exponent turns out to be a sensitive means for detecting Saharan dust events. The occurrence of SDE detected by this new method was confirmed by visual inspection of filter colors and by studying long-range backtrajectories. An examination of SDE over a 22-month period shows that SDE are more frequent during the March-June period as well as during October and November. The trajectory analysis indicated a mean traveling time of $96.5 \mathrm{~h}$, with the most important source countries situated in the northern and north-western part of the Saharan desert. Most of the SDE do not lead to a detectable increase of the 48-h total suspended particulate matter (TSP) concentration at the Jungfraujoch. During Saharan dust events, the average contribution of this dust to hourly TSP at the Jungfraujoch is $16 \mu \mathrm{g} / \mathrm{m}^{3}$, which corresponds to an annual mean of $0.8 \mu \mathrm{g} / \mathrm{m}^{3}$ or $24 \%$ of TSP.
\end{abstract}

Correspondence to: $\mathrm{M}$. Collaud Coen

(martine.collaud@meteoswiss.ch)

\section{Introduction}

Deserts are major sources of aerosol injected into the atmosphere, with mineral dust comprising more than $35 \%$ of the emitted primary aerosol mass (Houghton et al., 2001). Half of this amount is attributed to the Saharan desert and influences the aerosol loading of Africa, the Atlantic Ocean, South America, the East coast of USA, and Europe. Though poorly quantified, the impact of mineral dust on global radiative forcing is expected to be negative (Diaz et al., 2001; Myhre et al., 2003; Mahowald and Kiehl, 2003). Sources of radiative forcing uncertainties are the mineral aerosol shape (Kalashnikova and Sokolik, 2002), their optical properties as a function of wavelength (Sokolik and Toon, 1999), and their spatial, vertical and temporal distribution. In addition to its impact on radiative forcing, mineral dust influences the local rain/snow acidity and marine biochemical processes. Furthermore, harmful health effects due to elevated concentrations of total suspended particles (TSP) are also important and have been estimated in several studies (Avila et al., 1997; Rodriguez et al., 2001; Delmas et al., 1995; Prospero et al., 2002).

While most of the Saharan dust is transported westward and southward (about $60 \%$ ) by the Saharan Air Layer (SAL) and by lower layer transport in trade winds (Chiapello et al., 1997; Afeti and Resch, 2000), a non-negligible amount reaches Europe. D'Almeida (1986) estimated the Saharan dust transport to Europe to be $80-120 \mathrm{Mt} / \mathrm{yr}$. In Southern Europe, Saharan dust events (SDE) can induce up to 20 daily exceedances of the $\mathrm{PM}_{10}$ standard per year (Rodriguez et al., 2001). In northern countries, the influence of SDE is less

(C) 2004 Author(s). This work is licensed under a Creative Commons License. 
prominent, but also less understood. Studies performed in the Alps (Delmas et al., 1995; Schwikowski et al., 1995; De Angelis and Gaudichet, 1991; Maupetit and Davies, 1991; Wagenbach and Geis, 1989), as well as in England (Ryall et al., 2002) have pointed out the frequent occurrence of SDE resulting in an annual mean deposition of 0.4 to $1 \mathrm{gm}^{-2}$. In Switzerland, Schwikowski et al. (1995) analyzed the characteristics of a particular SDE in 1990 at the Jungfraujoch. To obtain a global view of the effect of mineral dust in Europe, it is however necessary to study the occurrence of SDE over long periods of time and trace their contribution to exceedances of the $\mathrm{PM}_{10}$ and TSP standards.

Trends of SDE in Europe have previously been evaluated by red rain, or dust content of snow and ice. While aerosol trapped in snow or ice may also originate from dry deposition, a red rain analysis takes into account only wet deposition. In all these cases, the importance of mineral dust in ambient air cannot reliably be estimated. Some studies evaluate the TSP and $\mathrm{PM}_{10}$ data and correlate them with chemical analysis and back trajectories to identify the source regions. Analysis of several years of data is also currently available with satellite measurements (Prospero et al., 2002). Other methods to identify Saharan dust include measurements of size distribution, granulometry, Lidar, aerosol optical depth (AOD) and the Angström parameter deduced from nephelometer or photometer measurements.

In this study, we evaluate a new SDE detection method, which is based on the investigation of the wavelength dependence of the single scattering albedo (SSA). The wavelength dependence of the scattering and absorption coefficients, and therefore of the single scattering albedo, and the Ångström parameter allows for the identification of characteristic features associated with SDE. The SDE identified by the SSA exponent method are correlated with visual inspection of the filter color and with back trajectories to identify the source regions. The analysis is based on measurements performed between March 2001 and December 2002 at the high-alpine research station of the Jungfraujoch (JFJ). An annual frequency and source frequency climatology analysis of this nearly two-year record is also performed, as well as an estimation of the Saharan dust contribution to annual and hourly TSP.

\section{Experimental}

Continuous measurements of a number of aerosol parameters have been performed since 1995 at the Global Atmospheric Watch (GAW) laboratory of the high alpine research station Jungfraujoch (JFJ, $3580 \mathrm{~m}$ a.s.1., $46^{\circ} 33^{\prime}, 7^{\circ} 59^{\prime}$ ), which is located on a mountain crest on the northern edge of the Swiss Alps. The JFJ is prevalently situated in the free troposphere, but is influenced by convection of planetary boundary layer air during the warmer months (Baltensperger et al., 1997; Lugauer et al., 1998). Consequently all the measured aerosol parameters show a clear annual cycle with maximum values in July and August and minimum values in the NovemberJanuary period. Except during the winter months, a diurnal cycle often exists as a result of the injection of planetary boundary layer aerosol into the free troposphere air during the afternoon.

According to measurements by MeteoSwiss during the last 20 years, the mean monthly temperature at the Jungfraujoch varies from $0^{\circ} \mathrm{C}$ (July to August) to $-13^{\circ} \mathrm{C}$ (January to February), the relative humidity (RH) from $64 \%$ (January) to $79 \%$ (May), while the mean barometric pressure is 663 mbar. The wind direction at the site is influenced by the NE-SW orientation of the local alpine watershed in the immediate vicinity, resulting in an average annual wind frequency of $60 \%$ from NW and $30 \%$ from SE.

The total aerosol is sampled by a heated inlet $\left(+25^{\circ} \mathrm{C}\right)$ designed to evaporate all cloud droplets at an early stage of the sampling process. Calculations for this set-up showed that cloud droplets smaller than $40 \mu \mathrm{m}$ can be sampled at a wind speed of $20 \mathrm{~m} \mathrm{~s}^{-1}$ (Weingartner et al., 1999). During cloud events, the total sample thus consists of dried particles that were activated to cloud droplets as well as the inactivated (interstitial) particles.

The total and backward scattering coefficients $\left(\sigma_{S P}\right.$ and $\left.\sigma_{B S P}\right)$ are simultaneously measured at three wavelengths $(\lambda=450,550$, and $700 \mathrm{~nm})$ by an integrating nephelometer (IN, TSI 3563). Data are collected with 5 min resolution from which hourly means are calculated. The scattering coefficients were corrected for the truncation error according to Anderson and Ogren (1998), taking into account the scattering exponent from the uncorrected scattering coefficient to calculate the appropriate correction factor for each wavelength. While the total error on the correction is still significant for coarse particles $(95 \%$ confidence bound $=17 \%$ for scattering exponent smaller than 1.5), it is very low for small particles (95\% confidence bound $=3 \%$ ) (Nessler et al., $2004^{1}$ ). The main uncertainty for coarse aerosol arises from the error on the determination of the vanishing scattering exponent.

The absorption coefficient $\left(\sigma_{a p}\right)$ was measured at seven wavelengths $(\lambda=370,470,520,590,660,880$ and $950 \mathrm{~nm})$ by an aethalometer (AE-31, Magee Scientific). $\sigma_{a p}$ was calculated with (Weingartner et al., 2003):

$\sigma_{a b s}=\frac{A}{Q} \times \frac{\Delta A T N}{\Delta t} \times \frac{1}{C}$

where $A$ is the filter spot area, $Q$ the volumetric flow rate and $\triangle A T N$ is the change in attenuation during the time interval $\Delta t$, and $C=2.14 \pm 0.2$ is a wavelength independent empirical correction factor, which corrects for the enhancement of the optical path in the filter due to multiple reflections of the

\footnotetext{
${ }^{1}$ Nessler, R., Weingartner, E., and Baltensperger, U.: Adaptation of dry nephelometer measurements to ambient conditions at the Jungfraujoch, Environ. Sci. Technol., in review, 2004.
} 
light beam at the filter fibers. The $\mathrm{C}$ factor used here was determined from different aerosol types such as soot particles generated by spark discharge, Diesel soot particles and externally mixed Diesel and $\left(\mathrm{NH}_{4}\right)_{2} \mathrm{SO}_{4}$ particles at $450 \mathrm{~nm}$ and $660 \mathrm{~nm}$ (Weingartner at al., 2003). The shadowing effect has been found to be negligible for aged particles and therefore can be completely neglected for particles arriving at the JFJ (Weingartner et al., 2003). Aethalometer data were collected with 10 min resolution from which hourly means were calculated. All times are given as local standard time LST (equal to $\mathrm{UTC}+1 \mathrm{~h}$ ). The measurements were performed at room temperature $\left(25 \pm 4^{\circ} \mathrm{C}\right)$, which corresponded to $\mathrm{RH} \leq 10 \%$. As a result, the measured scattering and absorption coefficients, as well as the calculated single scattering albedo and Ångström exponents, are related to the dried aerosols, and not to ambient outdoor aerosols.

To calculate the single scattering albedo, the scattering coefficients measured at three wavelengths are first fitted with a power-law dependence:

$\sigma_{s p}=b_{s p} \times \lambda^{-\alpha_{s p}}$,

which allows for the determination of the scattering exponent $\alpha_{s p}$. The scattering coefficient is then evaluated at the seven absorption coefficient wavelengths. The single scattering albedo (SSA) is calculated at these seven wavelengths and these SSA values are then fitted with a similar wavelength power-law to obtain the single scattering albedo exponent $\alpha_{\text {SSA }}$. A similar procedure results in the extinction coefficients at seven wavelengths, and the Ångström exponent å, which describes the extinction coefficient wavelength dependence. A wavelength power-law fit of the absorption coefficients yields the absorption exponent $\alpha_{a p}$.

Analyzed wind fields with a temporal separation of six hours were used to calculate three dimensional kinematic backward trajectories with the software package "Lagranto" (Wernli and Davies, 1997). The wind fields were provided by the European Centre for Medium-Range Weather Forecasts $(\mathrm{ECMWF})$ model with a resolution of $1^{\circ} \times 1^{\circ}$. The trajectories were resolved in 60-min time steps and their length was limited to 10 days backward in time. In order to account for transport at different altitudes and also for random deviations, the arrival points were varied both horizontally and vertically. In the horizontal dimension, the accurate location of the Jungfraujoch $\left(46.33^{\prime} \mathrm{N}, 7.59^{\prime} \mathrm{E}\right)$ was supplemented by 4 arrival points being displaced by $\pm 0.5^{\circ}$ in latitude and $\pm 0.5^{\circ}$ in longitude, respectively. In the vertical dimension, the levels at $650 \mathrm{hPa}$ (which is close to the annual mean pressure at Jungfraujoch), as well as 700, 750 and $800 \mathrm{hPa}$ were examined. Although 20 trajectories were calculated in total for each case, only trajectories indicating paths of air masses potentially contributing to the measured Saharan dust episode are shown in the figures. This criterion was chosen to take into account only those trajectories that include at least one time step within a $150 \mathrm{hPa}$ deep layer over the African continent.
The contribution of Saharan dust to the TSP mass concentration at the JFJ was estimated using 48-h filter samples of total suspended particles (TSP) collected at the JFJ by the Swiss National Air Pollution Monitoring Network (NABEL). The TSP samples were collected with a high-volume sampler, and the filters were automatically changed at midnight every second day.

Chemical characterization was achieved by collecting the aerosol in two size classes (TSP and particles with an aerodynamic diameter $\mathrm{D}<1 \mu \mathrm{m}$ (PM1)). The upper four stages of a cascade impactor (Maenhaut et al., 1996) allowed for a cut-off of $1 \mu \mathrm{m}$ with a constant flow rate of $11 \mathrm{~L} \mathrm{~min}^{-1}$. The concentrations of major ions were determined by ion chromatography after aqueous extraction (Henning et al., 2002).

\section{Results and discussion}

3.1 Determination of the SDE events by the wavelength dependence of the single scattering albedo

Figure 1 presents the scattering, absorption, and extinction coefficients as well as the single scattering albedo, for an individual SDE. The scattering coefficient is characterized by higher $\sigma_{s p}$ values as well as by a considerably smaller wavelength dependence during the SDE. An increase is also observed for the absorption coefficient, however the shift is smaller than for $\sigma_{s p}$. The wavelength dependence of the absorption coefficient has a tendency to increase during the SDE. As expected, the extinction coefficient has a similar behavior as the scattering coefficient, with a decrease of the wavelength dependence and an increase in intensity. The SSA values become higher for all wavelengths, and show a clear wavelength inversion between the 6.5.2001 at $18 \mathrm{~h} \mathrm{LST}$ and the 9.5.2001 at $3 \mathrm{~h} \mathrm{LST}$, with greater values for longer wavelengths. As it will be shown later, the inversion of the wavelength dependence can be attributed to the presence of Saharan dust and provides a method for detecting the occurrence of SDE.

The presented extinction coefficient is calculated from the measured scattering and absorption coefficients and its wavelength dependence yields the well-known Ångström exponent å:

$\sigma_{e x t}=\sigma_{s p}+\sigma_{a p}=b_{e x t} \times \lambda^{-\stackrel{̊}{a}}$

The SSA $\omega_{0}$ corresponds to the scattering part of the extinction coefficient. As both the scattering and the extinction coefficients can be fitted with a wavelength power-law dependence, the SSA can also be fitted in a similar way:

$\omega_{0}=\sigma_{s p} / \sigma_{e x t}=b_{\mathrm{SSA}} \times \lambda^{-\alpha_{\mathrm{SSA}}}=b_{\mathrm{SSA}} \times \lambda^{-\left(\alpha_{s p}-\stackrel{a}{)}\right)}$,

such that the SSA exponent is the difference between the scattering and the Ångström exponents. As seen in Fig. 2b, this power-law behavior of the SSA as a function of the wavelength agrees well with the data. 

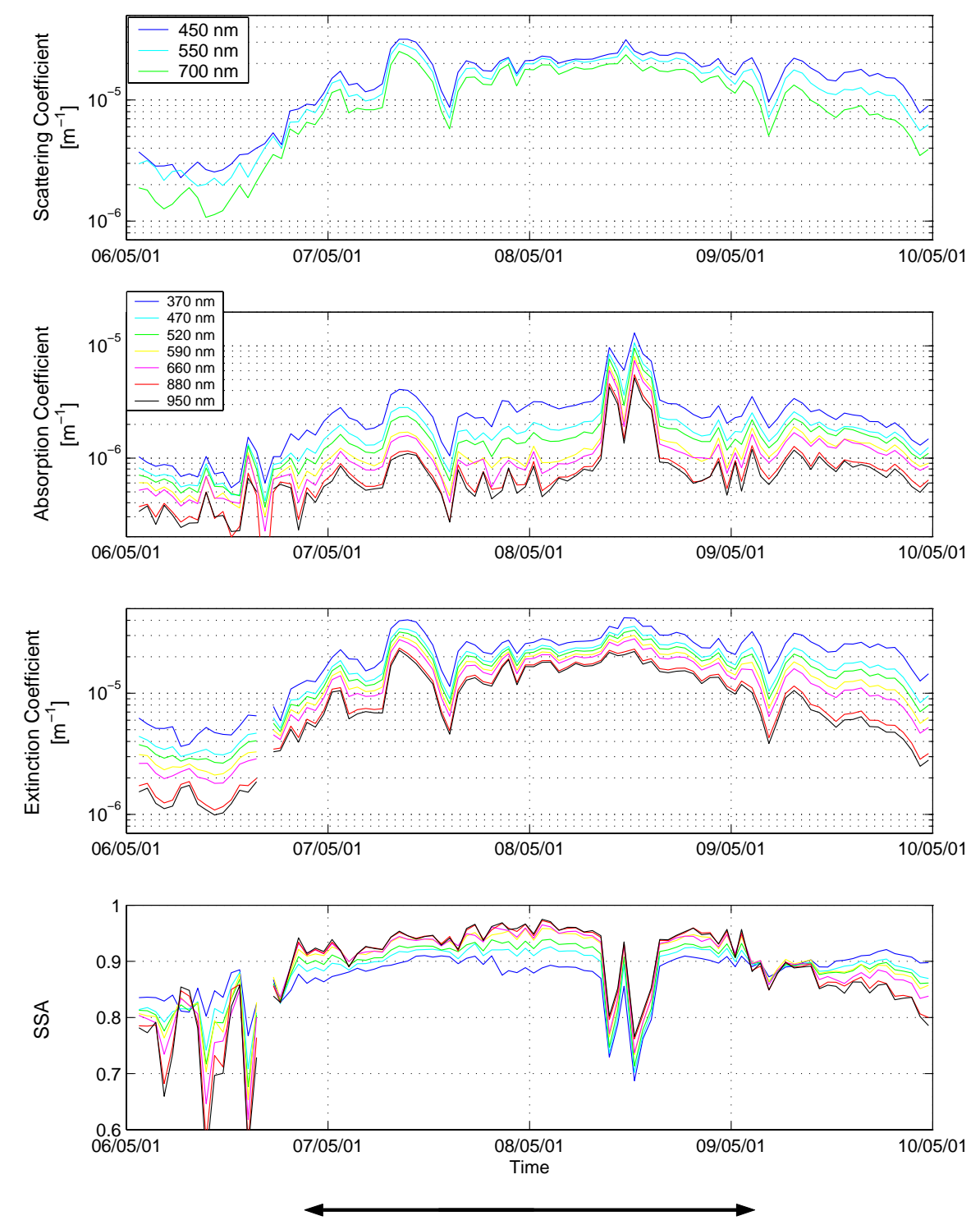

Saharan Dust Event

Fig. 1. Temporal evolution (hourly means) of the scattering, absorption and extinction coefficients, and the calculated single scattering albedo during a Sahara dust event (6 to 10 May 2001).

For aerosols that do not contain large particles, the scattering coefficient usually decreases more rapidly with increasing wavelength than the absorption coefficient. As a result, $\alpha_{s p}$ is greater than å and $\alpha_{\mathrm{SSA}}$ is positive. Conversely, when coarse particles are present, the scattering becomes dominated by geometrical optics, such that a wavelength independence of the scattering coefficient is expected (Seinfeld and Pandis, 1998) as seen in our data. The exponent of the absorption coefficient $\left(\alpha_{a p}\right)$ is usually estimated to stay constant at 1-1.2 (Seinfeld and Pandis, 1998, Bergstrom et al., 2002), but we actually measured an increase of the absorption wavelength dependence (Fig. 2a). The Ångström ex- ponent å will therefore approach zero less rapidly than $\alpha_{s p}$, which results in a negative $\alpha_{\text {SSA }}$ during SDE.

The wavelength dependence is visualized in Fig. 3, where the exponents of all parameters are reported for the same time period. The values of $\alpha_{s p}$ and å are usually between 1 and 2.5. During the SDE they are clearly shifted below 1 , and most of the time below 0.5. At the same time, $\alpha_{a p}$ increases up to 1.5 , which is higher than its normal value of about 1 . Consequently, the resulting $\alpha_{\text {SSA }}$ becomes clearly negative during SDE with values usually falling between -0.1 and -0.5 . In this study, SDE are defined as time periods that exhibit negative $\alpha_{\mathrm{SSA}}$ for more than $3 \mathrm{~h}$. 
Table 1. Exponents of the absorption coefficient before (5.5.2001), during (7-8.5.2001) and after (11.5.2001) a Saharan dust event, resulting from the fit of the four lowest or the four highest wavelengths.

\begin{tabular}{|l|l|l|l|l|}
\hline & 5.5 .2001 & 7.5 .2001 & 8.5 .2001 & 11.5 .2001 \\
\hline$\alpha_{\text {ap }}$ for the 4 lowest wavelengths & 1.04 & 1.84 & 1.48 & 1.10 \\
\hline$\alpha_{\text {ap }}$ for the 4 highest wavelengths & 1.10 & 0.94 & 1.00 & 1.07 \\
\hline
\end{tabular}
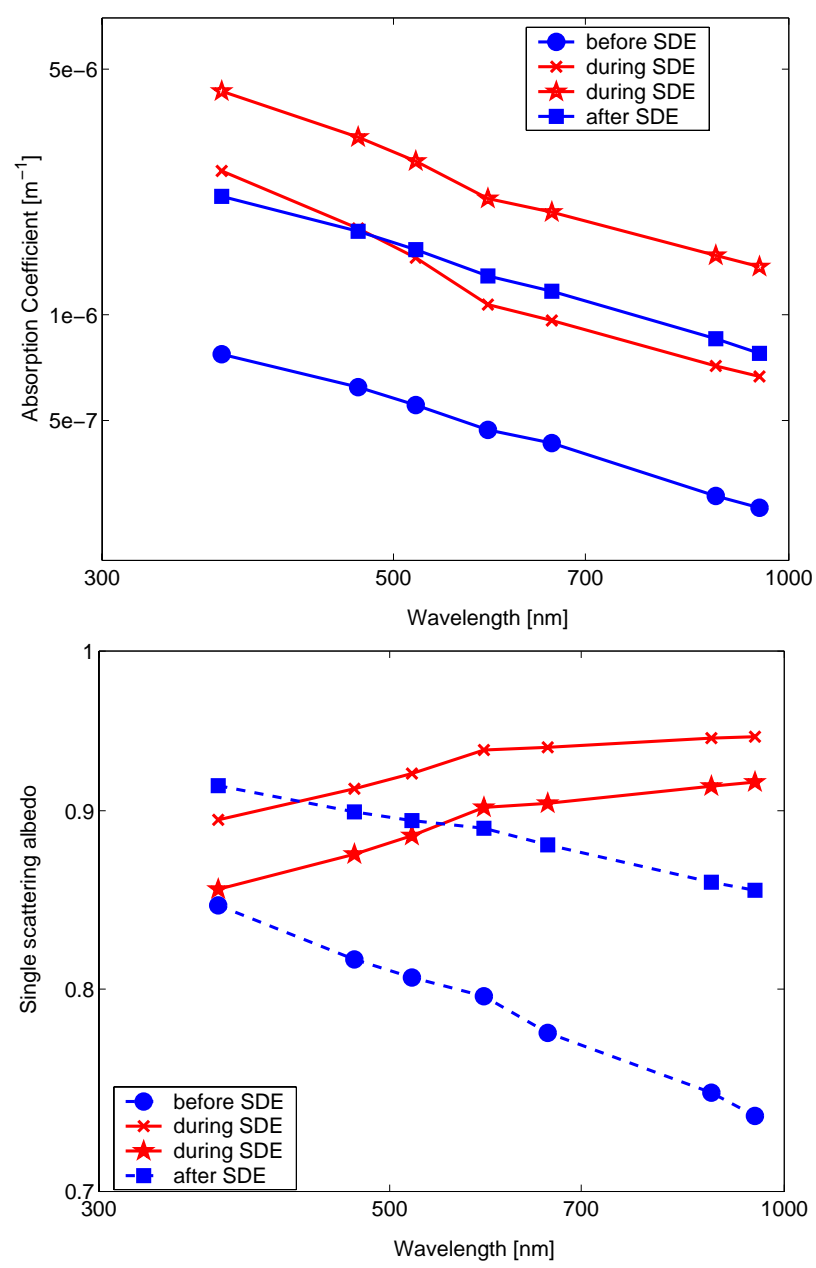

Fig. 2. Log-log plots of daily means of a) the absorption coefficient and b) the single scattering albedo as a function of the wavelength for (black square) the day before the SDE (5.5.2001), for (asterisk and star) SDE days (7-8.5.2001), and for (black circle) a stable day after the SDE (11.5.2001).

The possible identification of mineral dust events by $\alpha_{\text {SSA }}$ values was conceived using theoretical considerations (Bergstrom et al., 2002). The absorption coefficient measured using the integrating sandwich method during the Tropical Aerosol Radiative Forcing Observational Experiment (TARFOX) at the eastern coast of the United State shows an approximate $\lambda^{-1}$ variation between 0.4 and $1.0 \mu \mathrm{m}$, but with a quicker decrease between 0.4 and $0.6 \mu \mathrm{m}$

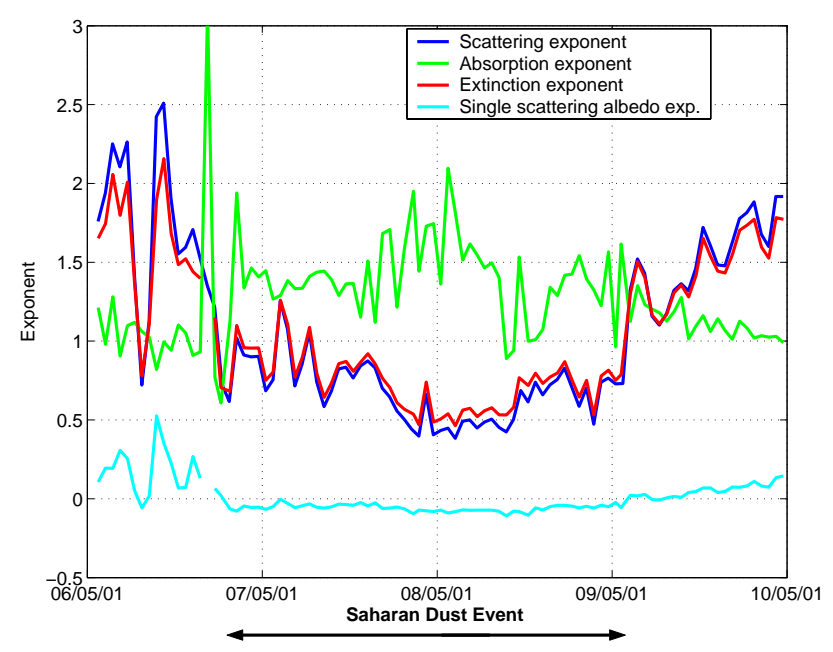

Fig. 3. Exponents of the scattering, absorption and extinction coefficient, along with the single scattering albedo exponent during the same Sahara dust event (6.5.2001-10.5.2001).

and a leveling off at longer wavelengths. The same applies to our data of the Jungfraujoch (Fig. 2a). The greater wavelength dependence in the lower $\lambda$ range during SDE can be explained by the chemical composition of the aerosols. About $89 \%$ of the mass of Saharan dust is composed of illite, kaolinite and montmorillonite minerals (Sokolik and Toon, 1999), as well as of hematite (Quijano et al., 2000). Hematite (a strong absorber at solar wavelengths) aggregated with the other three clay materials (relatively transparent at solar wavelengths) results in a generally greater absorption, particularly at shorter wavelengths. Table 1 gives the exponents of the power-law fit when only the lowest four or the highest four wavelengths of the aethalometer are taken into account. For days without SDE, both slopes are nearly identical, giving a value close to 1 . When mineral dust is present, the fit of the lowest four wavelengths exhibits far higher exponent values (1.5-1.8).

The inversion of the SSA wavelength dependence was also calculated for several mineral dust species and for various sizes (Sokolik and Toon, 1999). They simulated the spectral behavior of illite, kaolinite and montmorillonite dusts with diameters between 0.25 and $0.7 \mu \mathrm{m}$ and obtained a sharp increase in the SSA for wavelengths up to $0.6 \mu \mathrm{m}$ and a constant value above $0.6 \mu \mathrm{m}$. In contrast, hematite showed a slightly decreasing SSA up to $0.6 \mu \mathrm{m}$ and a strong increase 
Table 2. Exponents of the single scattering albedo before (5.5.2001), during (7-8.5.2001) and after (11.5.2001) a Saharan dust event, resulting from the fit of the four lowest or the four highest wavelengths.

\begin{tabular}{|l|l|l|l|l|}
\hline & 5.5 .2001 & 7.5 .2001 & 8.5 .2001 & 11.5 .2001 \\
\hline$\alpha_{\text {SSA }}$ for the 4 lowest wavelengths & 0.17 & -0.14 & -0.17 & 0.08 \\
\hline$\alpha_{\text {SSA for the 4 highest wavelengths }}$ & 0.22 & -0.03 & -0.06 & 0.12 \\
\hline$\alpha_{S S A}$ for all wavelengths & 0.20 & -0.08 & -0.11 & 0.09 \\
\hline
\end{tabular}

Table 3. Percentage of SDE detected by different methods (SDE detected by the $\alpha_{\text {SSA }}$ method set to $100 \%$ ).

\begin{tabular}{|l|l|l|l|l|l|}
\hline Parameters & $\alpha_{\text {SSA }}$ negative & $\alpha_{\text {sc }}$ lower & $\sigma_{\text {sc }}$ higher & $\alpha_{\text {ap }}$ higher & $\sigma_{\text {ap }}$ higher \\
\hline Clarity & $100 \%$ & $80 \%$ & $60 \%$ & $\begin{array}{l}42.5 \% \\
(2 \% \text { missing })\end{array}$ & $\begin{array}{l}47.5 \% \\
(2 \% \text { missing })\end{array}$ \\
\hline
\end{tabular}

above $0.6 \mu \mathrm{m}$. The SSA wavelength dependence observed during mineral dust events at the JFJ, as seen in Fig. $2 b$ and Table 2, presents a more negative slope between 0.37 and $0.6 \mu \mathrm{m}$ than for longer wavelengths. Comparing this behavior to the predictions by Sokolik and Toon (1999), we can attribute the strong increase at shorter wavelengths to illite, kaolinite and montmorillonite, and the second slighter increase to hematite, even though the latter constitutes a relatively small fraction of the total Saharan dust mass.

A similar SSA behavior was measured by ground-based sun/sky radiometers in the Persian Gulf by Smirnov et al. (2002) and in three desert regions by Dubovik et al. (2002). While a clear wavelength inversion was reported by Dubovik et al. (2002), a wavelength independence or a slight increase of the SSA with wavelength was observed by Smirnov et al. (2002). In the case, however, only a very small increase was visible in the monthly mean SSA for May 1999. This virtual wavelength independence was correlated with low Ångström exponents (0.4-0.7) and corresponded to the seasonal period with the highest mineral dust concentration.

As mentioned in the experimental part, operational measurements at the JFJ are performed on dry aerosols. Thus the SSA absolute magnitude of the ambient (outdoor) aerosol will usually be higher than the measured one due to the absence of liquid water on the particles. On the other hand, the effect of the water content on the wavelength dependence is expected to be less important for a number of reasons. First, the negative value of $\alpha_{\mathrm{SSA}}$ arises principally from the wavelength independence of $\sigma_{s p}$ which is due to the dominance of the large aerosol particles. As the diameter of particles becomes larger with enhanced humidity, a similar $\sigma_{s p}$ spectral behavior will be measured for wet mineral dust. In some cases, smaller dry aerosol particles, which are currently not detected as SDE, could exhibit a wavelength independent scattering coefficient if ambient relative humidity is high enough to allow for significant water uptake. Second, hygroscopic growth factors are smaller for SDE particles than for the common JFJ aerosol (Weingartner et al., 2001). Third, it has been shown that the wavelength dependence of the absorption coefficient is very similar in the $0.45-1.0 \mu \mathrm{m}$ region for externally mixed, internally mixed and shell-core configurations of black carbon (Jacobson, 2000). Since the aerosol reaching the JFJ is aged and therefore internally mixed, $\alpha_{a p}$ will probably exhibit only a slight variation with humidity. Consequently, although all the measurements are performed on dried aerosols, the sign of $\alpha_{\text {SSA }}$ can still be used to identify SDE at the Jungfraujoch with a time resolution of one hour.

As can be seen in Fig. 2b and Table 2, the SSA exponent of the first four shorter wavelengths is consistently more negative than the exponent of the four longer wavelengths. This allows the estimation of a fitting error on the whole measured wavelength range. The $\alpha_{\mathrm{SSA}}$ difference between the shorter and longer wavelength sets is typically $\leq 0.1$. Using only some of the wavelengths may therefore change the SDE limits by a few hours, but does not yield a false SDE detection.

\subsection{Influence of Saharan dust events on all exponents}

The SDE described in the previous paragraph is a typical one, where all parameters exhibit clear modifications compared to normal conditions. Nonetheless, some detected SDE are less pronounced or do not present all of the previously described features. Table 3 gives the percentage of events where the measured optical coefficients and all the derived parameters were modified by SDE, where $100 \%$ correspond to all cases detected by a negative $\alpha_{\text {SSA }}$ longer than $3 \mathrm{~h}$.

SDE induce a decrease of $\alpha_{s p}$ in $80 \%$ of the cases and an obvious increase of the $\sigma_{s p}$ during a part or the whole of the SDE in $60 \%$. The measurement of the scattering coefficients is therefore the second most efficient parameter to detect the presence of mineral dust. Usually, $\alpha_{s p}$ values fall between 0.5 and 1 during SDE, yet negative values are also occasionally observed. In these cases, the observed increase of the scattering coefficient with increasing wavelength $\left(1 \times 10^{-7}\right.$ to 
$\left.5 \times 10^{-6} \mathrm{~m}^{-1}\right)$ is clearly greater than the measurement uncertainties $\left(5 \times 10^{-8} \mathrm{~m}^{-1}\right)$.

An increase of $\alpha_{a p}$ is observed in less than half of the SDE $(42 \%)$, and higher $\sigma_{a p}$ values are seen in $47 \%$ of all cases. These changes of $\alpha_{a p}$ and $\sigma_{a p}$ occur for both short and long dust events. No correlation with aerosol travel time or with source regions was found. If enough black carbon is mixed with the mineral dust, the measured wavelength dependence can be dominated by black carbon, and the mineral dust features disappear. The change of the absorption coefficient and its wavelength dependence during SDE are therefore less frequent and are not considered as useful identification tools.

As is the case for $\alpha_{s p}$, the Ångström exponent decreases for most of the SDE cases, due to the large size of dust particles. Values between 0 and 1 are usually measured for dried mineral aerosols, but negative values also occur. These values correspond well with the Ångström exponents measured in the presence of mineral dust (Takemura et al., 2002; Smirnov et al., 2002). Sokolik and Toon (1999) calculated the extinction coefficient for 0.5 and $0.7 \mu \mathrm{m}$ diameter aerosol particles of illite, kaolinite, montmorillonite, hematite, quartz, calcite and gypsum and found a continuous increase with respect to wavelength for all mineral dust types between 0.2 and at least $1 \mu \mathrm{m}$, which is equivalent to a negative Ångström exponent. Some photometer measurements have also shown negative Ångström exponents in the Sahel region (Holben at al., 2001).

3.3 Validity of SDE detection by negative $\alpha_{\mathrm{SSA}}$ : comparison with filter color and back-trajectory analysis

To corroborate the inversion of the wavelength dependence of the single scattering albedo during SDE, the color of TSP filters from the Jungfraujoch and 10-day back-trajectories (see Sect. 3.5) were studied and the results compared to our set of measurements. The TSP level at the Jungfraujoch remains very low during the whole year, with annual means between 3 and $5 \mu \mathrm{g} / \mathrm{m}^{3}$ for the last 10 years (BUWAL, 2001). This low amount of aerosol allows for the identification of heavy SDE by a distinct brown-yellow deposit on the filters. The temporal resolution of these filters is $48 \mathrm{~h}$, which is far worse than the resolution obtained with the SSA exponent.

An obvious coloration of the filter was observed for $57 \%$ of the SDE, while the color was unclear for $19 \%$ of the cases. For $7 \%$ of SDE, the filters were missing. Therefore, only $17 \%$ of the events detected by the $\alpha_{\mathrm{SSA}}$ method clearly showed no filter coloration. However, all these inconsistent dust events lasted only 4 to $6 \mathrm{~h}$ and were generally characterized as "disturbed" events, where even the wavelength dependence and to a lesser extent the coefficients themselves showed a high hourly variability. These events appear to correspond to weak SDE, where the mineral dust mass is too small to change the filter color. All but one of the events with unclear filter coloration also correspond to relatively short SDE (4-12 h), even though some of these events present clear
SDE features for all other parameters. Consequently, the filter coloration method is an acceptable means for validating the detection of SDE using the sign of $\alpha_{\mathrm{SSA}}$, but it is far less sensitive and has significant limitations with respect to SDE duration.

Two events showed a filter color change without modification of the other parameters $\left(\alpha_{s p}, \sigma_{s p}, \alpha_{a p}, \sigma_{a p}\right.$ and particularly $\alpha_{\mathrm{SSA}}$ ). For both cases the TSP mass was relatively high. Back-trajectory analyses gave a positive result for one of these events, and a negative one for the other. Pollen contamination was excluded as the cause of the filter coloration. The positive SSA exponent during these two SDE could possibly be explained by a smaller size of the Saharan dust.

In $71 \%$ of all cases, the 10-day back-trajectories were able to reveal the source of Saharan dust. Among the other 29\% of cases, the trajectories did not pass over Africa and were often fairly dispersed. For one event, the back-trajectories passed far too high over Africa to catch Saharan dust.

Taking into account the trajectories and the filter color, $74 \%$ of the SDE were confirmed. For the remaining cases, satellite pictures (www.nrlmry.navy.mil/aerosol/ satellite/seawifs) of the 2-6 days before the detected SDE were visually inspected. In 7\%, a clear emission of Saharan dust towards Europe, usually towards Italy or Sardinia, was visible. In one case (2\%), none of the former methods was available to confirm the event. Finally, only $8 \%$ of all cases remained unconfirmed by either of the three methods. The negative SSA exponent can therefore without doubt be attributed to the occurrence of Saharan dust events. This new detection method seems to be most sensitive, first because of its hourly resolution and second because the observed changes in optical properties can also be detected for low aerosol concentrations.

\subsection{Climatology of SDE between March 2001 and Decem- ber 2002}

The estimation of the wavelength dependence of the single scattering albedo over a period of nearly two years allows for a first analysis of the SDE climatology at the JFJ. Figure 4 presents the number of hours per month that Saharan dust was detected during the interval of March 2001-December 2002. Two distinct periods of high SDE probability can be defined: one in spring from March to June and one in October and November. During the December-February period, SDE are far less frequent, last only a few hours (maximum $6 \mathrm{~h}$ ) and are often characterized with indistinct features (see Sect. 3.2). Some occasional but quite intense cases occur in July and August, but none occurred in September for both years. A particularly long period that comprised several SDE of multiple days occurred between 10 October and 22 November 2001. This specific event was also detected in England (Ryall et al., 2002) and in Germany (Mattis et al., 2002). 


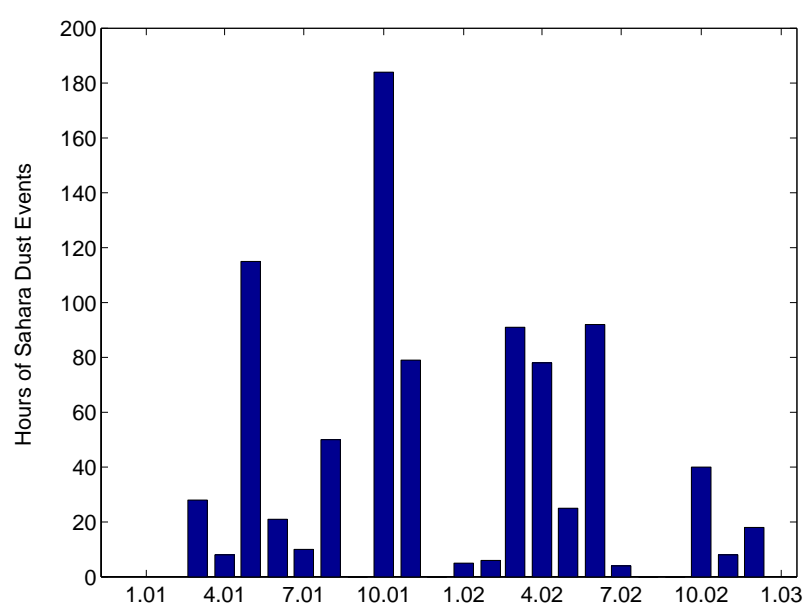

Fig. 4. Number of hours of Saharan dust occurrences detected by the negative exponent of the single scattering albedo for each month of the studied period.

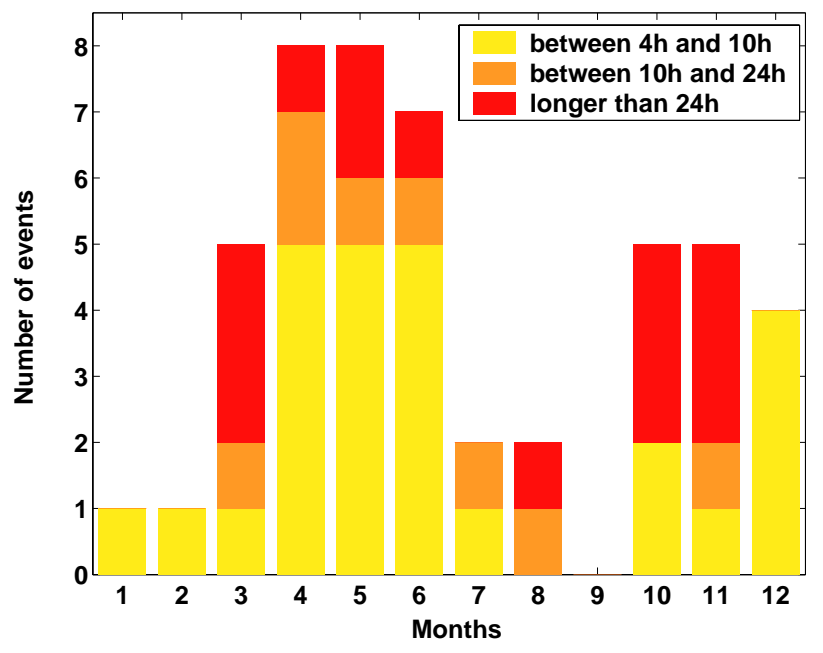

Fig. 5. Climatology of the number of Saharan dust events classified by their duration.

A two-year average estimate of the length of the episodes for each month is given in Fig. 5. Again, one can clearly see that the majority of events lasting longer than $10 \mathrm{~h}$ occur during the March-June and October-November periods. Similarly, most events lasting longer than one day also take place during these two periods. Overall, $54 \%$ of the recorded SDE lasted between $4 \mathrm{~h}$ and $10 \mathrm{~h}, 17 \%$ between $10 \mathrm{~h}$ and $24 \mathrm{~h}$, and $29 \%$ were longer than one day.

A non exhaustive comparison with other Saharan dust measurements in Europe, the Mediterranean basin, West Africa, and over the Atlantic Ocean is summarized in Table 4. Also included in the Table is an estimation of the Saharan emission intensity (Marticorena and Bergametti, 1996; D'Almeida, 1986) which allows for a rough correlation with the measurements at the JFJ. Most of the studies performed in Europe report a higher incidence of SDE and the greatest mineral dust deposition during spring with less frequent occurrences in July and August. SDE show highest intensity during summer only in Spain and in the central Pyrenees. Both facts were explained by Moulin et al. (1998). While most of the eastern and central Mediterranean SDE occur in the March-June period, the western part of Europe is mostly influenced by SDE during July and August. The JFJ is mostly affected by Saharan dust transport via the eastern and central Mediterranean and, to a much smaller extent, via the western Mediterranean. During these spring and summer periods, dust transport through the Saharan Air Layer (SAL) affects the whole Atlantic region. This phenomenon also induces the transport of Saharan dust to the JFJ from north-west direction.

September generally shows a very low amount of SDE all over Europe. The same applies for the December-February period, except in Spain. During winter, the emission of Saharan dust is low and its transport occurs mostly through low altitude trade winds over West Africa (Harmattan season) and the Atlantic.

A high number of SDE in October and November is also observed in Catalonia as well as in Spain, Corsica, Tuscany, and Germany (L. Schütz, Mainz, personal communication), and to a smaller extent at the Mont-Blanc. For this time of the year the Saharan emissions are normally very low. The October 2001 case was probably a particularly intense event.

\subsection{Back trajectories of the SDE}

Generally, when transport over larger distances takes place, the air has been lifted up by a frontal system associated with conveyor belts to higher tropospheric levels (Bethan et al., 1998; Stohl and Trickl, 1999). For all calculated trajectories that confirmed an SDE (38 cases), typical traveling heights were investigated by extracting the largest vertical distance of the trajectory from the ground in $\mathrm{hPa}$ (i.e. the pressure difference between trajectory height and the ground level in $\mathrm{hPa}$ ). The resulting uplift was between 250 and $550 \mathrm{hPa}$, which corresponds to heights between 2500 and $6500 \mathrm{~m}$ a.s.l., respectively. The mean uplift was $375 \mathrm{hPa}$ corresponding to about $3700 \mathrm{~m}$ a.s.l. When a frontal system and its associated conveyor belts induce an uplift, this is reflected in the vertical trajectory paths. In these cases the minimal traveling times of the air masses containing Saharan dust particles can be estimated as the time between the start of the uplifting (after residing near-ground over the Sahara) and the arrival at the Jungfraujoch. On average, this minimal traveling time was about $96.5 \mathrm{~h}$. The shortest traveling time was around $50 \mathrm{~h}$. On the other hand, extremely long transport times of up to 8 days were also found (see e.g. the SDE on 28 March 2002 described below).

For each case confirming an event, a potential source country was identified if the criterion given in the 
Table 4. Annual distribution of Saharan dust events at the JFJ, Europe, the Mediterranean basin, West Africa, the Atlantic, and the overall annual distribution of the Saharan dust emissions. References: 1) De Angelis and Gaudichet, 1991; 2) Avila et al., 1997; 3) Ryall et al., 2002; 4) Rodriguez et al., 2001; 5) Mattson and Nihlèn, 1996; 6) Moulin et al., 1998; 7) Loÿe-Pilot and Martin, 1996; 8) Bellandi et al., 1996; 9) Moulin et al., 1998; 10) Afeti et Resch, 2000; 11) Chiapello et al., 1999; 12) Marticorena et al., 1997; Marticorena and Bergametti, 1996; 13) D'Almeida, 1986.

\begin{tabular}{|l|l|l|l|l|l|l|l|l|l|l|l|l|l|}
\hline & January & February & March & April & May & June & July & August & September & October & November & December \\
\hline JFJ & Very low & Very hents & & \\
\hline
\end{tabular}

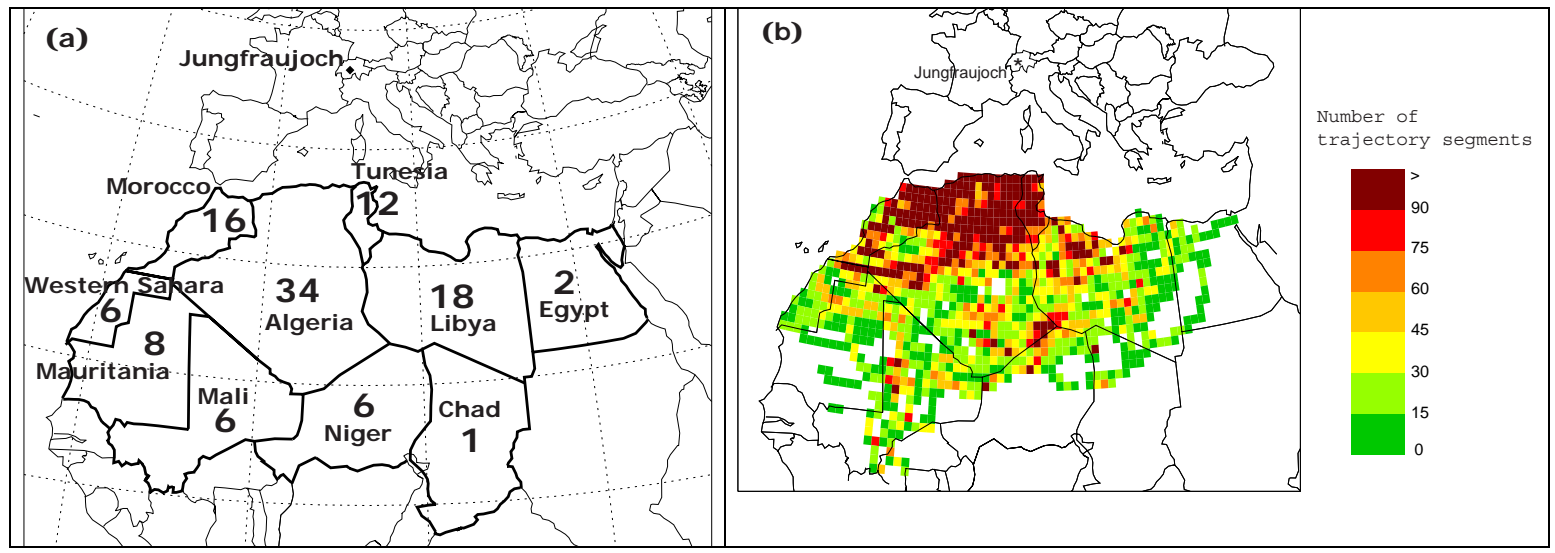

Fig. 6. The most important source countries of SDE at the Jungfraujoch. The numbers indicate the numbers of trajectories being situated at least once over the respective country in a vertical distance from ground of less than $150 \mathrm{hPa}$ (a). Numbers of trajectory segments (hourly time steps) in a vertical distance from ground of less than $150 \mathrm{hPa}$ in a $0.75^{\circ} \times 0.75^{\circ}$ grid (b)

experimental section of this manuscript was fulfilled over the country. As expected, the most important potential source countries (Fig. 6a) are situated in the northern and northwestern part of the Saharan desert with the most cases found in Algeria (34 cases out of 38) which means that almost every SDE in Switzerland had at least a potential source region in Algeria. Figure $6 \mathrm{~b}$ indicates the numbers of trajec- tory segments (i.e. the hourly trajectory time steps) counted in a $0.75^{\circ} \times 0.75^{\circ}$ grid superimposed over the domain if the given criterion was fulfilled. Again, the north-north-western part of Africa with Morocco, Algeria, Tunisia, and Libya was the most important source region of the Saharan dust detected at the JFJ. Figure 7 shows the same numbers separated by season. It seems that during spring and summer, the 


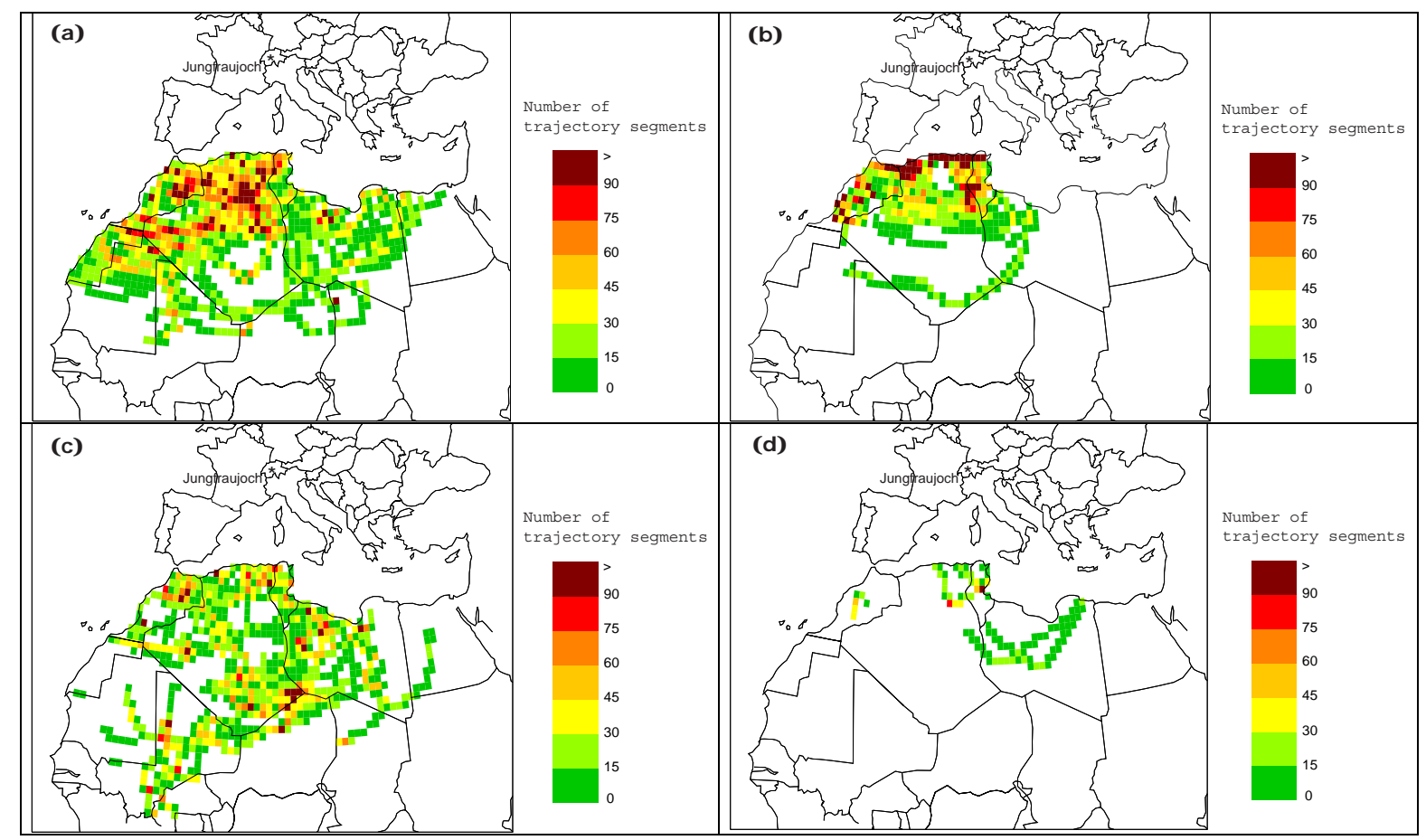

Fig. 7. Same numbers of trajectory segments as in Fig. 6 for March-May (a, 17 cases), June-August (b, 9 cases), September-November (c, 9 cases) and December-February (d, 3 cases).

sources are mostly located in the northern part of north and north-west Africa, whereas in autumn, the source regions are much more extended towards the south. A similar seasonal behavior was found by Prospero et al. (2002) who showed that the most active dust source regions are situated more in North Africa during summer and move south-west during the September to January period. The numbers of cases in each season are too small to support these results by carrying out a proper statistical analysis. Nevertheless, if the meteorological transport conditions were the same throughout the year, one would expect more potential source regions in the south for the spring events since this period produced the highest number of cases. Therefore, we would suggest these weak source differences between seasons to be linked with different meteorological transport conditions or different activity of the source regions.

The direction of the air mass inflow to the JFJ was investigated by visual inspection of the trajectories and classifying them into the four sectors given in Table 5. Again, the relatively small number of cases prevents a statistical significance. Nevertheless, as expected, the inflows from the two southern sectors are most important in all seasons. This air mass movement is often associated with low pressure systems and their cold-fronts approaching Europe from the Atlantic. These weather patterns - often associated with SouthFoehn events in the Alps - accelerate the air masses towards the JFJ. In north-western inflow cases, the air moves from the
Sahara towards the Atlantic, turns to the north and flows towards the Alps with prevailing westerly winds. Only two cases $(5 \%)$ were found with an inflow direction from the north-eastern sector. In these cases, the air moves northward to higher latitudes before turning southward again and approaching the JFJ from north-east or east. These SDE also exhibited the longest traveling times of up to 8 days. In the following section, two cases of Saharan dust transport to Switzerland are discussed in more detail.

\subsubsection{SDE on 13 October 2001}

A particularly long SDE occurred at the JFJ from 11 October 2001 at $17 \mathrm{~h}$ LST to 18 October 2001 at $13 \mathrm{~h} \mathrm{LST}$. This pronounced event was also detected by a LIDAR and a CIMEL sun photometer in Germany (Müller et al., 2003). Figure 8 shows the trajectories arriving at the Jungfraujoch on 13 October 2001. From 3 to 7 October, a flat pressure distribution prevailed over Africa and induced slow air mass movements over a large part of north-western Africa. At the same time, an extremely strong low pressure system traveled over the Northern Atlantic and reached Western Europe on 7 October, and an extended cold-front reaching from Denmark to Morocco moved south-eastward. This frontal system generated an air flow towards the northern direction. Together with an increasing velocity, the vertical trajectory paths in Fig. 8 indicate an uplift of the air masses up to $500 \mathrm{hPa}$ pressure 
Table 5. Inflow directions at the Jungfraujoch described by four sectors in percent of total cases.

\begin{tabular}{|l|c|c|c|c|}
\hline & $\begin{array}{c}0^{\circ}-90^{\circ} \\
(\mathrm{N}-\mathrm{E})\end{array}$ & $\begin{array}{c}90^{\circ}-180^{\circ} \\
(\mathrm{E}-\mathrm{S})\end{array}$ & $\begin{array}{c}180^{\circ}-270^{\circ} \\
(\mathrm{S}-\mathrm{W})\end{array}$ & $\begin{array}{c}270^{\circ}-360^{\circ} \\
(\mathrm{W}-\mathrm{N})\end{array}$ \\
\hline all cases (38) & 5 & 37 & 40 & 18 \\
\hline March - May (17) & 12 & 47 & 29 & 12 \\
\hline June - August (9) & 0 & 11 & 67 & 22 \\
\hline September - November (9) & 0 & 33 & 45 & 22 \\
\hline December - February (3) & 0 & 67 & 0 & 33 \\
\hline
\end{tabular}

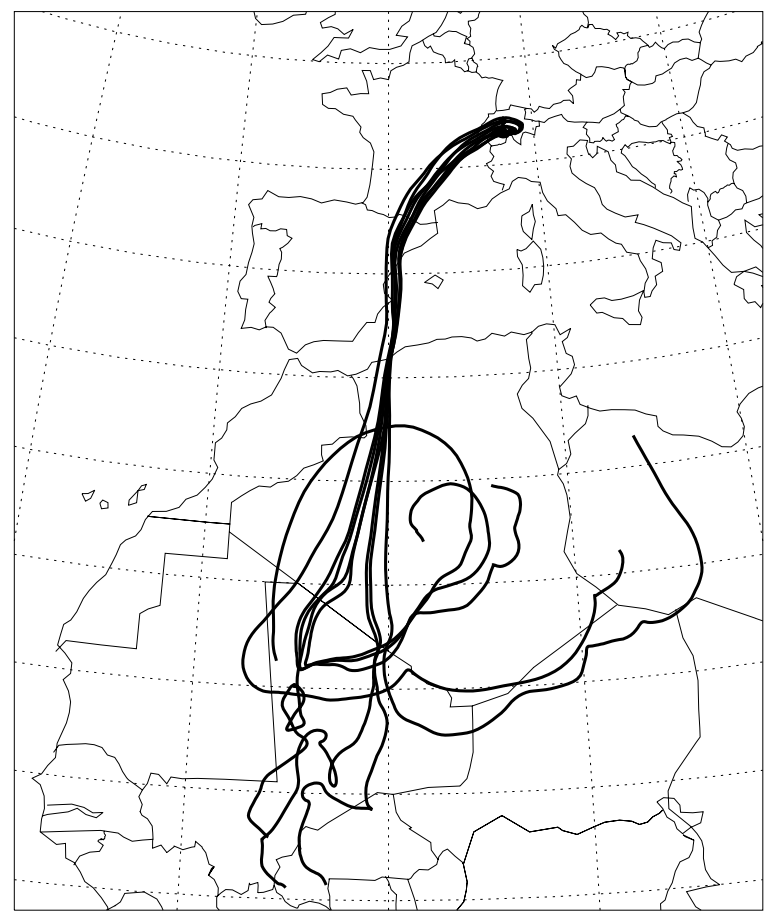

Back trajectory arrival

13 Oct 2001, 12:00 UTC

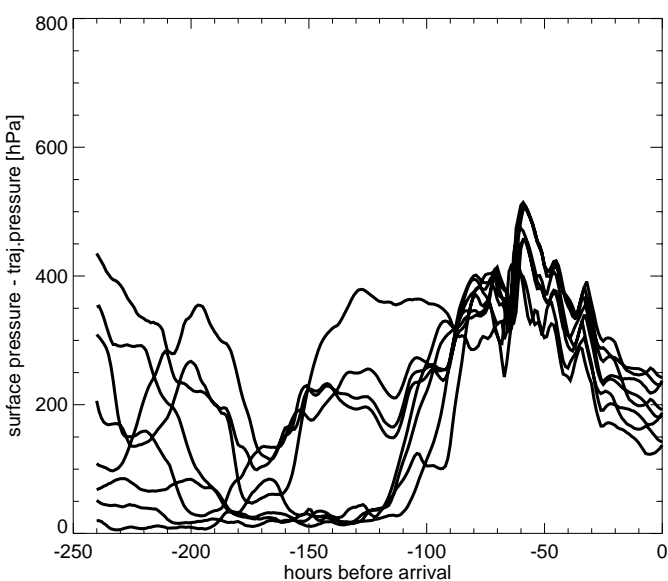

Fig. 8. 10-day backward trajectories arriving at the Jungfraujoch on 13 October 2001, 13:00 LTC. This example demonstrates the frontal uplift of the air masses during their transport to the Jungfraujoch.

level (about $5500 \mathrm{~m}$ a.s.l.). From 8 to 10 October, the strong pressure system moved slowly eastward over Great Britain to the North Sea. The cold-front passed over the Alps and was divided into a cold-front north of the Alps further moving eastward and - together with an upcoming South-Foehn in the Alps - a warm front over the Alps. From 11 October on, a high pressure system installed over Central Europe and forced the air masses coming from the Sahara to subside and to turn clockwise to south-eastern flow direction before arriving at the JFJ.

\subsubsection{SDE on 28 March 2002}

The backward trajectories of Fig. 9 are representative of a SDE that lasted several days at the end of March 2001. This case is quite specific as the traveling time exceeds 8 days. The air masses started over Algeria, Niger and Mauritania 10 days before arrival and moved relatively slowly in a clock- wise motion around a high pressure system centered over Morocco. During 21 March, the air masses came under the influence of low pressure systems over the Atlantic. The air was lifted up to the altitude of 400 to $550 \mathrm{hPa}$ (4000 to $6500 \mathrm{~m}$ a.s.l.). The air flow accelerated and reached a latitude of 70 degrees after only two days. At this point, the air masses started to turn clockwise due to a high pressure system over Scandinavia. The high pressure core moved further southward over Denmark and installed over northern Germany. This induced a clockwise air flow over Scandinavia, Russia and the Eastern European countries that was associated with a strong subsidence during the last days before arrival. Finally, the trajectories reached the JFJ from an easterly direction, which is not very typical for Saharan dust events and were found only twice in our study. 


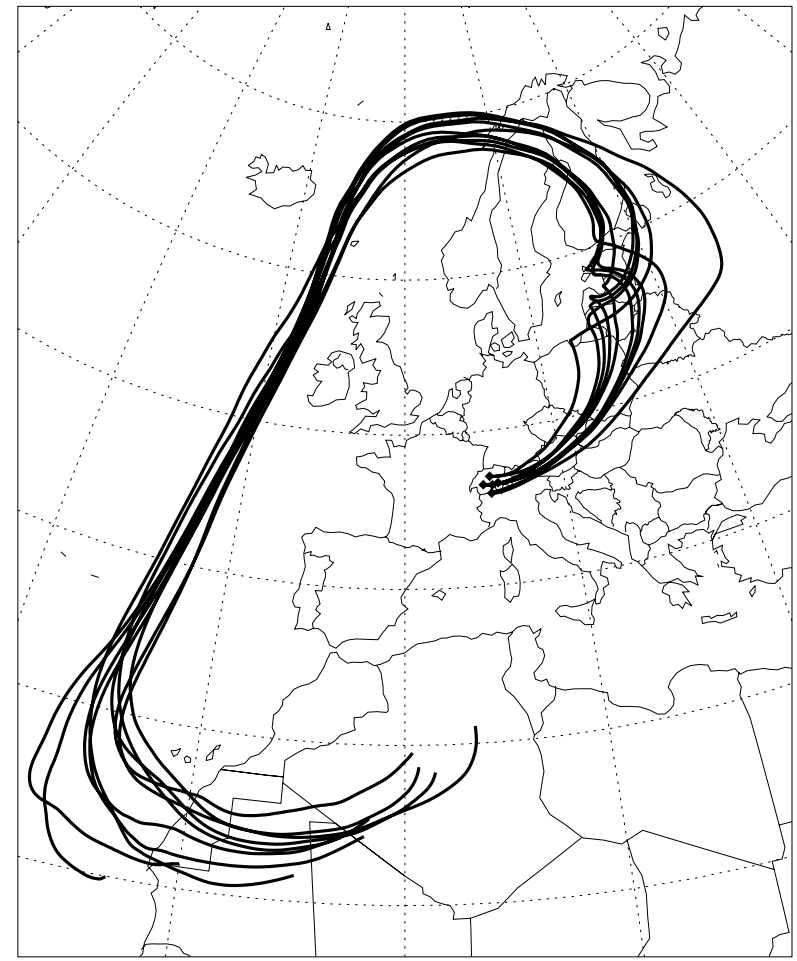

Back trajectory arrival

28 Mar 2002, 12:00 UTC

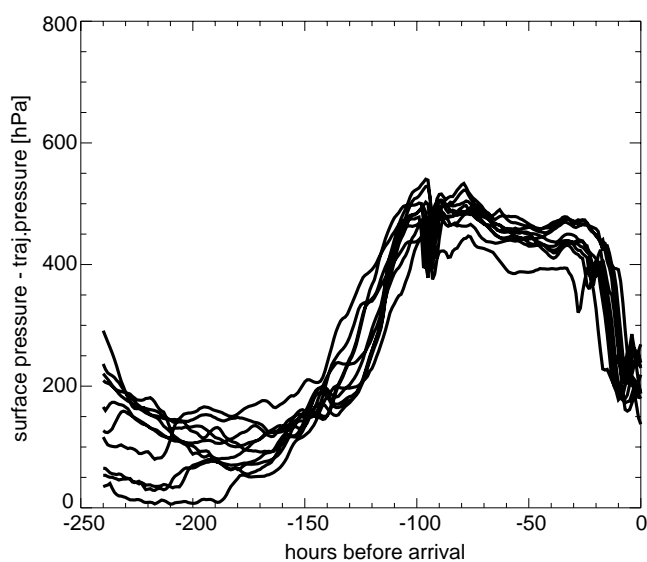

Fig. 9. 10-day backward trajectories arriving at the Jungfraujoch on 28 March 2002, 13:00 LTC. Again, the frontal uplift can clearly be seen. The flow direction from north-eastern direction to the Jungfraujoch is somewhat surprising.

\subsection{Estimation of the Saharan dust contribution to TSP}

Saharan dust events significantly contribute to the 48-h TSP level at the JFJ. For the time period from 01 March 2001 to 31 December 2002, the average TSP concentration of 48-h samples that were not affected by SDE was $2.5 \mu \mathrm{g} / \mathrm{m}^{3}$, while for samples collected during an SDE period the TSP mean value was $7.3 \mu \mathrm{g} / \mathrm{m}^{3} .25 \%$ of the samples that were affected by SDE were higher than $10 \mu \mathrm{g} / \mathrm{m}^{3}$ compared to $1.6 \%$ of the samples that were not affected. However, for a large fraction of the filter samples that were affected by SDE, the TSP level was moderate. $64 \%$ of the SDE affected samples had a 48-h TSP value below $5.5 \mu \mathrm{g} / \mathrm{m}^{3}$, which corresponds to the 90-percentile of the 48-h TSP samples without SDE. Therefore, the 48-h TSP mass concentration is not an appropriate measure for identifying SDE.

From the length of each SDE (determined by the negative SSA exponent as shown above) the time not affected by SDE was calculated for each of these samples. For this unaffected time, a TSP value was estimated with a local linear regression model using the loess function of the statistical software R (Chambers and Hastie, 1992). The smoothing parameter was chosen to minimize the residual standard error of the regression function. From the calculated unaffected TSP value and the corresponding time, the non-SDE fraction was calculated for all SDE affected 48-h TSP samples. Subtracting this value from the total 48-h TSP mass concentration then yielded the SDE contribution to each 48-h TSP value. The estimates are expected to be accurate when the sequences of successive SDE affected and/or missing filter samples are not too long. Multiple linear regression and generalized additive models (Chambers and Hastie, 1992) were not used here, because they showed large residuals for high TSP mass concentrations.

Figure 10 shows the measured 48-h TSP mass concentration, the local linear regression function, and the estimated non-SDE fraction for all SDE affected TSP samples. The uncertainty of the estimates for the non-SDE fraction of 48h TSP was investigated by splitting the measured 48-h TSP mass concentrations that are not affected by SDE into a training and a test set. A local linear regression model was specified by use of the training set and the model accuracy was then evaluated by applying the model to the test set. The resulting residuals were normally distributed with a mean value of zero and a standard deviation of $1.8 \mu \mathrm{g} / \mathrm{m}^{3}$. Consequently, the uncertainty for the estimation of the non-SDE fraction of 48-h TSP samples is $3.6 \mu \mathrm{g} / \mathrm{m}^{3}$ (at 95\% confidence level). Moreover, the standard deviation of the gravimetric 48-h TSP measurement at the JFJ, as derived from repeated determinations, is $1.0 \mu \mathrm{g} / \mathrm{m}^{3}$. The total uncertainty based on the summation of the squares of the individual standard deviations is thus $4.1 \mu \mathrm{g} / \mathrm{m}^{3}$ (at 95\% confidence level). 


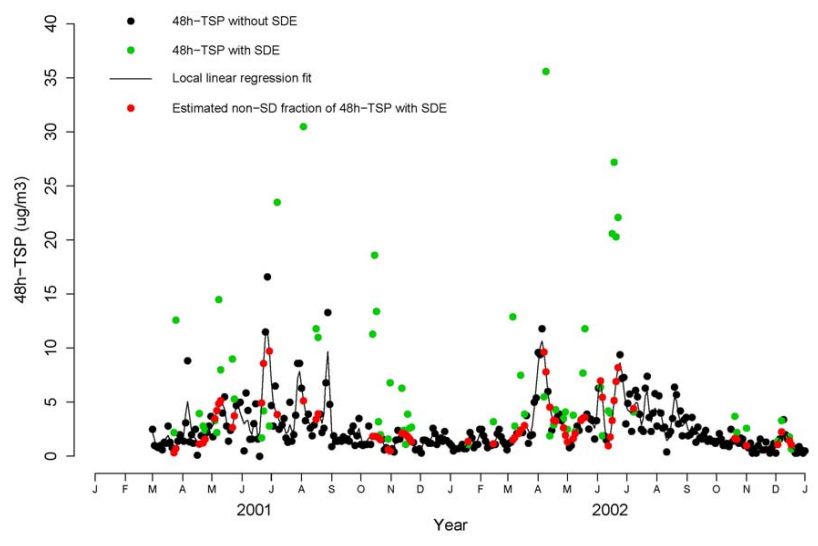

Fig. 10. Measured and estimated 48-h TSP mass concentrations between 1 March 2001 and 31 December 2002 at the JFJ. Shown are the measured values for samples that are not affected by Saharan dust (black dots), and for samples that are identified as being affected by Saharan dust (green dots). The line is the estimated local linear regression function. The red dots are the estimates for the non-SDE fraction of 48-h TSP samples that are affected by SDE.

For 19 out of the 67 identified SDE, the estimated contribution of Saharan dust to the 48-h TSP values was above $5 \mu \mathrm{g} / \mathrm{m}^{3}$. However, most of the estimated SDE contributions to the 48-h TSP values were lower than the uncertainty of the estimate, and negative values for the estimated Saharan dust contribution occurred for 15 of the 67 identified SDE. The uncertainty range of all except two of the negative values included zero. The two lowest values concerned two consecutive SDE separated by 4 days and were due to an overestimated background concentration between the two events. Even though negative values are physically not reasonable, they were not removed (or set to zero) for the subsequent averaging process, because this would induce a positive bias.

The annual average contribution of SDE to the TSP values at the JFJ was then estimated as the arithmetic mean of the determined Saharan dust contributions to the 48-h TSP values. Evidently, the Saharan dust contribution to 48-h TSP samples not affected by SDE was set to zero. For the total analyzed time period, the average contribution of Saharan dust to TSP at the JFJ was found to be $0.8 \mu \mathrm{g} / \mathrm{m}^{3}\left( \pm 0.2 \mu \mathrm{g} / \mathrm{m}^{3}\right)$. With a mean TSP level of $3.4 \mu \mathrm{g} / \mathrm{m}^{3}$ this corresponds to about $24 \%$.

The available 48-h TSP samples are certainly not ideal for investigating the contribution of SDE. A higher temporal resolution would be advantageous since the duration of SDE at the JFJ is typically much shorter than $48 \mathrm{~h}$. The contribution of Saharan dust to the TSP concentration during an SDE cannot be resolved by this approach. However, an average SDE contribution to hourly TSP values during SDE can be calculated from the length of each SDE (in hours) and the SDE contribution to each 48 -h TSP value. Figure 11 shows the calculated contribution of Saharan dust to hourly TSP for

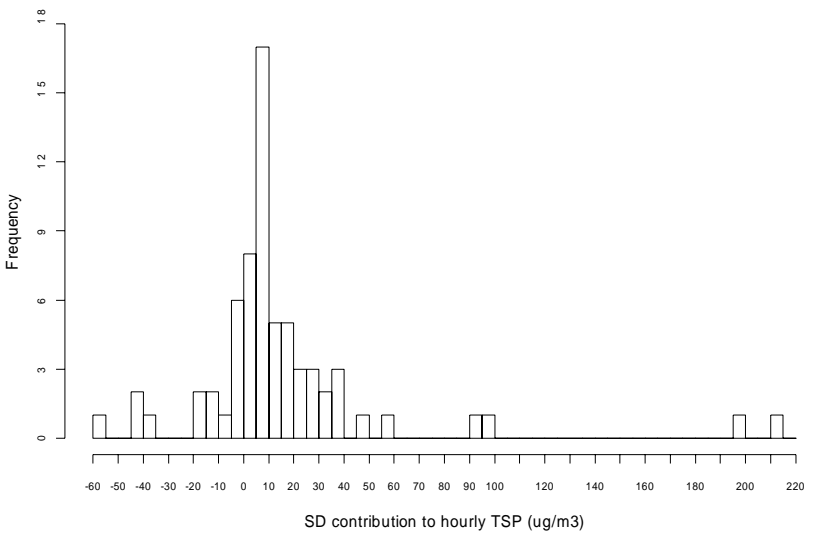

Fig. 11. Distribution of the estimated Saharan dust contribution to hourly TSP concentrations during SDE at the JFJ. Negative values for the Saharan dust contribution to hourly TSP are physically not reasonable, but a consequence of the applied model. They are not removed (or set to zero) because this would yield a positive bias.

the identified SDE. The average contribution of SDE to the hourly TSP value at the JFJ is $16.1 \mu \mathrm{g} / \mathrm{m}^{3}$. For about one third of the identified SDE the Saharan dust contribution to hourly TSP is below $5 \mu \mathrm{g} / \mathrm{m}^{3}$, and for $60 \%$ of the SDE, it is below $10 \mu \mathrm{g} / \mathrm{m}^{3}$. On the other hand, $9 \%$ of the SDE lead to a Saharan dust contribution of above $40 \mu \mathrm{g} / \mathrm{m}^{3}$, with a maximum contribution of $214 \mu \mathrm{g} / \mathrm{m}^{3}$ resulting from the SDE on 20 June 2002.

\subsection{Chemical analysis}

For the March-November 2001 period, 24-h filter samples were collected on every sixth day and analyzed for chemical composition by ion chromatography (Henning et al., 2002). This chemical analysis was performed in total on 23 filters, and in $25 \%$ of these cases SDE were identified by the inversion of the SSA wavelength dependence. As in the case of the TSP values, the SDE often corresponded only to a part of the filter sampling time, so that the SDE contribution to the chemical composition was diluted by the normal aerosol. Some general conclusions can still be deduced from these measurements. Table 6 presents the daily average mass concentrations of analyzed species with and without SDE, for TSP and PM1, as well as the ratios with/without SDE of the species concentrations in percent. Negative values in the coarse mode may be explained with the uncertainties resulting from the difference between two relatively large numbers.

During SDE, the concentrations of magnesium, calcium and potassium are significantly enhanced, which is explained by the fact that these are all constituents of illite and montmorillonite. This is mainly seen in TSP and to a far lesser extent in PM1, confirming that SDE mainly affect the coarse mode. It is however interesting to note that SDE exhibits 
Table 6. Mass concentrations of analyzed species with and without SDE, for TSP and PM1 (columns 2-5), and the ratios with/without SDE of the concentrations in percent for TSP, PM1 and coarse mode aerosols (last three columns). All data are from 24-h samples. The coarse mode ratio was calculated from the TSP-PM1 difference. The last line accounts for the fact that by volatilization of $\mathrm{NH}_{4} \mathrm{NO}_{3}$ from the Teflon filter NH4 is lost as well, which can be corrected using the nitrate data from the Nylon filter.

\begin{tabular}{|c|c|c|c|c|c|c|c|}
\hline & \multicolumn{2}{|c|}{$\begin{array}{l}\text { Concentration } \\
\text { during SDE } \\
\left(\mathrm{ng} / \mathrm{m}^{3}\right)\end{array}$} & \multicolumn{2}{|c|}{$\begin{array}{l}\text { Concentration } \\
\text { without SDE } \\
\left(\mathrm{ng} / \mathrm{m}^{3}\right)\end{array}$} & \multicolumn{3}{|c|}{$\begin{array}{c}\text { Ratio with/without SDE } \\
(\% / \%)\end{array}$} \\
\hline & TSP & PM1 & TSP & PM1 & $\begin{array}{l}\text { Total } \\
\text { (TSP) }\end{array}$ & PM1 & Coarse mode \\
\hline Total & 2893.8 & 498.9 & 821.0 & 378.1 & - & - & - \\
\hline $\mathrm{F}^{-}$ & 2.91 & 0.65 & 0.73 & 0.29 & 1.13 & 1.67 & 0.52 \\
\hline $\mathrm{CH}_{3} \mathrm{COO}^{-}$ & 46.7 & 0.07 & 2.46 & 0.02 & 5.37 & 2.97 & -6.99 \\
\hline $\mathrm{HCOO}^{-}$ & 6.54 & 0.44 & 2.32 & 0.21 & 0.80 & 1.61 & 0.55 \\
\hline $\mathrm{CH}_{3} \mathrm{SO}_{3}^{-}$ & 4.21 & 1.16 & 2.42 & 0.89 & 0.49 & 0.98 & 0.32 \\
\hline $\mathrm{Cl}^{-}$ & 34.13 & 1.54 & 6.82 & 0.69 & 1.41 & 1.68 & 1.25 \\
\hline $\mathrm{NO}_{3}^{-}$ & 452.70 & 20.60 & 50.56 & 9.20 & 2.54 & 1.20 & 0.83 \\
\hline $\mathrm{NO}_{3}{ }^{-}$Nylon & 102.79 & 58.04 & 135.33 & 55.26 & 0.21 & 0.80 & -0.01 \\
\hline $\begin{array}{l}\mathrm{NO}_{3}^{-} \\
\text {(Teflon+Nylon) }\end{array}$ & 555.49 & 78.64 & 185.89 & 64.46 & 0.85 & 0.92 & 0.54 \\
\hline $\mathrm{SO}_{4}{ }^{2-}$ & 702.62 & 273.19 & 346.14 & 209.23 & 0.57 & 0.98 & 0.66 \\
\hline $\mathrm{C}_{2} \mathrm{O}_{4}{ }^{2-}$ & 34.00 & 2.15 & 5.13 & 1.40 & 1.88 & 1.16 & 1.84 \\
\hline $\mathrm{Na}^{+}$ & 80.40 & 4.51 & 11.15 & 1.92 & 2.04 & 1.77 & 0.89 \\
\hline $\mathrm{K}^{+}$ & 33.35 & 9.00 & 4.98 & 3.23 & 1.20 & 2.11 & 1.40 \\
\hline $\mathrm{Mg}^{2+}$ & 33.83 & 1.89 & 4.99 & 0.06 & 1.92 & 22.56 & 0.97 \\
\hline $\mathrm{Ca}^{2+}$ & 1043.54 & 26.95 & 96.63 & 2.77 & 3.06 & 7.35 & 1.81 \\
\hline $\mathrm{NH}_{4}^{+}$ & 286.12 & 81.86 & 111.93 & 76.88 & 0.72 & 0.80 & 0.31 \\
\hline $\begin{array}{l}\mathrm{NH}_{4}^{+} \text {plus } \mathrm{NO}_{3}^{-} \\
\text {Nylon }\end{array}$ & 316.04 & 98.75 & 151.32 & 92.96 & 0.44 & 0.81 & 0.12 \\
\hline
\end{tabular}

a significant fraction in the fine mode, resulting in a much higher increase of these components in PM1 than in the coarse mode. This submicron fraction exhibits a high surface area with basic sites (carbonates) which are available for neutralization reactions of acidic gases (Henning et al., 2002). This may explain the increase of acetate and formate in PM1 during SDE. For other components, especially for those of anthropogenic origin, differences are more difficult to interpret since their concentrations during SDE can highly vary depending on the actual trajectory of the air mass.

\section{Conclusions}

Saharan dust events can be detected with one-hour time resolution by the inversion of the wavelength dependence of the single scattering albedo. The resulting negative exponent of the SSA is due to the large size of mineral aerosols, which induces a wavelength independence of the scattering coefficient. Similarly a somewhat larger wavelength dependence of the absorption coefficient is linked to the Saharan dust chemical composition. Clear SDE are characterized by four factors: 1) an increase of the scattering, absorption and extinction coefficients, 2) vanishing scattering and Ångström exponents, 3) a larger absorption exponent and 4) a negative SSA exponent. According to this study, SDE at the JFJ lasted between only a few hours and seven days. In $92 \%$ of all cases, SDE detected by this new method are corroborated by either filter coloration, back-trajectory analysis, satellite measurements or a combination of these methods. The $\alpha_{\text {SSA }}$ method is however the most sensitive method to detect SDE. SDE are more frequent and last longer during the March-June and the October-November period, although some events also occur during the summer. Trajectory analysis shows that mineral dust traveling times are typically between 2 and 8 days, with a mean value of $96.5 \mathrm{~h}$. The main source countries of Saharan dust arriving at the JFJ are Algeria, Libya, Morocco and Tunisia. In only $31 \%$ of the cases, the contribution of Saharan dust to the 48-h TSP levels at the JFJ can be detected. The estimated average contribution of Saharan dust events to hourly TSP at the JFJ is $16 \mu \mathrm{g} / \mathrm{m}^{3}$, with the most severe SDE reaching $214 \mu \mathrm{g} / \mathrm{m}^{3}$. On average, the contribution of Saharan dust to the TSP concentration at the JFJ was $0.8 \mu \mathrm{g} / \mathrm{m}^{3}$ corresponding to $24 \%$ of TSP.

Acknowledgements. We thank the International Foundation High Altitude Research Stations Jungfraujoch and Gornergrat (HFSJG), which made it possible to PSI to carry out the experiments at the High Altitude Research Station at the Jungfraujoch. We also gratefully acknowledge Robert Gehrig (EMPA), who provided the filter color data for this study, H. Wernli for the software package "Lagranto" and for his support concerning trajectories, and P. Jeannet (MeteoSwiss) for the average annual meteorological conditions at the JFJ. This work was supported by MeteoSwiss within the Swiss programme to the Global Atmospheric Watch (GAW) of the World Meteorological Organization.

Edited by: S. Martin 


\section{References}

Afeti, G. M. and Resch, F. J.: Physical characteristics of Saharan dust near the Gulf of Guinea, Atmos. Environ., 34, 1273-1279, 2000.

Anderson, T. L. and Ogren, J. A.: Determining aerosol radiative properties using the TSI 3563 Integrating Nephelometer, Aerosol Sci. Technol. 29, 57-69, 1998.

Avila, A., Queralt-Mitjans, I., and Alarcòn, M.: Mineralogical composition of African dust delivered by red rains over northeastern Spain, J. Geophys. Res., 102, 21 977-21 996, 1997.

Baltensperger, U., Gäggeler, H. W., Jost, D. T., Lugauer, M., Schikowski, M., Weingartenr, E., and Seibert, P.: Aerosol climatology at the high-alpine site Jungfraujoch, Switzerland, J. Geophys. Res., 102, 19707-19715, 1997.

Bellandi, S., Oppo, C., Udisti, R., and Pantani, F.: Quasi-seasonal neutralization of acid rain in Tuscany: can Saharan dust be responsible?, in: The Impact of Desert Dust Across the Mediterranean, edited by: Guerzoni, S. and Chester, R., pp. 369-373, Kluwer Academic Publishers, Dordrecht, 1996.

Bergstrom, R. W., Russel, P. B., and Hignet, P.: Wavelength dependence of the absorption of black carbon particles: predictions and results from the TARFOX experiment and implications for the aerosol single scattering albedo, J. Atmos. Sci., 59, 567-577, 2002.

Bethan, S., Vaughan, G., Gerbig, C., Volz-Thomas, A., Richer, H., and Tiddeman, D. A.: Chemical air mass differences near fronts, J. Geophys. Res., 103, 13 413-13 434, 1998.

BUWAL, OFEFP, Office Fédéral de l'Environnement, des Forêts et du Paysage, NABEL : la pollution de l'air 2001, Cahier de l'environnement, 343, 2002.

Chambers, J. M. and Hastie, T. J.: Statistical Models in S., Wadsworth \& Brooks/Cole, Advanced Books and Software, Pacific Grove, California, 1992.

Chiapello, I., Prospero, J. M., Herman, J. R., and Hsu, N. C.: Detection of mineral dust over the North Atlantic Ocean and Africa with the Nimbus 7 TOMS, J. Geophys. Res., 104, 9277-9291, 1999.

Chiapello, I., Bergametti, G., Chatenet, B., Bousquet, P., Dulac, F., and Santos Soares, E.: Origins of African dust transported over the northeastern tropical Atlantic, J. Geophys. Res., 102, $13701-$ $13709,1997$.

D’Almeida, G. A.: A model for Saharan dust transport, J. Clim. Appl. Meteorol., 25, 903-916, 1986.

De Angelis, M. and Gaudichet, A.: Saharan dust deposition over Mont Blanc (French Alps) during the last 30 years, Tellus, 43, 61-75, 1991.

Delmas, V., Jones, H. G., Tranter, M., and Delmas, R.: The weathering of aeolian dust in alpine snows, Atmos. Environ., 30, 13171325,1995

Diaz, J. P., Exposito, F. J., Torres, C. J., Herrera, F., Prospero, J. M., and Romero, M. C.: Radiative properties of aerosols in Saharan dust outbreaks using ground-based and satellite data: applications to radiative forcing, J. Geophys. Res., 106, 18 403-18416, 2001.

Dubovik, O., Holben, B., Eck, T. F., Smirnov, A., Kaufman, Y. J., King, M. D., Tanré, D., and Slutsker, I.: Variability of absorption and optical properties of key aerosol types observed in worldwide locations, J. Atmos. Sci., 59, 590-608, 2002.
Henning, S., Weingartner, E., Schwikowski, M., Gäggeler, H. W., Gehrig, R., Hinz, K. P., Trimborn, A., Spengler, B., and Baltensperger, U.: Seasonal variation of the water soluble ions of the aerosol at the high-Alpine site Jungfraujoch (3580 m a.s.1.), J. Geophys. Res., 107, doi:10.1029/2002JD002439, 2002.

Holben, B. N., Tanré, D., Smirnov, A., Eck, T. F., Slutsker, I., Abuhassan, N., Newcomb, W. W., Schafer, J. S., Chatenet, B., Lavenu, F., Kaufman, Y. J., Vande Castle, J., Setzer, A., Markham, B., Clark, D., Frouin, R., Halthore, R., Karneli, A., O’Neill, N.T., Pietras, C., Pinker, R. T., Voss, K., and Zibordi, G.: An emerging ground-based aerosol climatology: aerosol optical depth from AERONET, J. Geophys. Res., 106, 12 067-12 097, 2001.

Jacobson, M. Z.: A physically based treatment of elemental carbon optics: implications for global direct forcing of aerosols, Geophys. Res. Lett., 27, 217-220, 2000.

Kalashnikova, O. V. and Sokolik, I. N.: Importance of shapes and compositions of wind-blown dust particles for remote sensing at solar wavelengths, Geophys. Res. Lett., 29, 38-1-38-4, 2002.

Loÿe-Pilot, M. D. and Martin, J. M.: Saharan dust input to the western Mediterranean: an eleven years record in Corsica, in: The Impact of Desert Dust Across the Mediterranean, edited by: Guerzoni, S. and Chester, R., pp. 191-199, Kluwer Academic Publishers, Dordrecht, 1996.

Lugauer, M., Baltensperger, U., Furger, M., Gäggeler, H. W., Jost, D. T., Schikoswki, M., and Wanner, H.: Aerosol transport to the high Alpine sites Jungfrauhoch (3454 m a.s.l.) and Colle Gnifetti (4452 m a.s.1.), Tellus Series B, Chemical and Physical Meteorology, 50B, 76-92, 1998.

Maenhaut, W., Hillamo, R., Mäkelä, T., Jaffrezo, J. L., Bergin, M. H., and Davidson, C. I.: A new cascade impactor for aerosol sampling with subsequent PIXE analysis, Nucl. Instrum. Methods Phys Res., 109B, 482-287, 1996.

Mahowald, N. and Kiehl, L.: Mineral aerosol and cloud interactions, Geophys. Res. Lett., 30, 1475, doi:10.1029/2002GL016762, 2003.

Marticorena, B. and Bergametti, G.: Two-year simulations of seasonal and interannual changes of the Saharan dust emissions, Geophys. Res. Lett., 23, 1921-1924, 1996.

Marticorena, B., Bergametti, G., and Aumont, B.: Modeling the atmospheric dust cycle, 2. Simulation of Saharan dust sources, J. Geophys. Res., 102, 4387-4404, 1997.

Mattis, I., Ansmann, A., Müller, D., Wandinger, U., and Althausen, D.: Dual-wavelength Raman lidar observations of the extinctionto-backscatter ratio of Saharan dust, Geophys. Res. Lett., 29, doi:10.1029/2002GL014721, 2002.

Mattson, J. O. and Nihlèn, T.: The transport of Saharan dust to southern Europe: a scenario, J. Arid Env., 32, 111-119, 1996.

Maupetit, F. and Davies, T. D.: Chemical composition and fluxes of wet deposition at elevated site (700-3105 m a.s.1.) in the eastern Alps (Discussion), in: Seasonnal Snowpacks: Processes of Compositional Change, edited by: Davies, T. D., Tranter, M., and Jones, H. G., NATO ASI Series G: Ecological Sciences, vol 28, pp. 299-302, Springer, Heidelberg, 1991.

Moulin, C., Lambert, C. E., Dayan, U., Masson, V., Ramonet, M., Bousquet, P., Legrand, M., Balkanski, Y. J., Guelle, W., Maticorena, B., Bergametti, G., and Dulac, F.: Satellite climatology of African dust transport in the Mediterranean atmosphere, J. Geophys. Res., 103, 13 137-13 144, 1998. 
Müller, D., Mattis, I., Wandiger, U., Ansmann, A., Althausen, D., Dubovik, O., Eckhardt, S., and Stohl, A.: Saharan dust over a central European EARLINET-AERONET site: Combined observations with Raman lidar and sun photometer, J. Geophys. Res., 108, 4345, doi:10.1029/2002JD002918, 2003.

Myhre, G., Grini, A., Haywood, J. M., Stordal, F., Chatenet, B., Tanre D., Sundet, J. K., and Isaksen, I. S. A.: Modeling the radiative impact of mineral dust during the Saharan Dust Experiment (SHADE) campaign, J. Geophys. Res., 108, 8579, doi:10.1029/2002JD002566, 2003.

Prospero, J. M., Ginoux, P., Torres, O., Nocholson, S. E., and Gill, T. E.: Environmental characterization of global sources of atmospheric soil dust identified with the nimbus 7 total ozone mapping spectrometer (TOMS) absorbing aerosol product, Rev. Geophys., 40, 1 February 2002.

Quijano, A., Sokolik, I. N., and Toon, O.B .: Radiative heating rates and direct radiative forcing by mineral dust in cloudy atmospheric conditions, J. Geophys. Res., 105, 12 207-12 219, 2000.

Rodriguez, S., Querol, X., Alastuey, A., Kallos, G., and Kakakiagou, O.: Saharan dust contribution to PM10 and TSP levels in Southern and Eastern Spain, Atmos. Environ., 35, 2433-2447, 2001.

Ryall, D. B., Derwent, R. G., Manning, A. J., Redington, A. L., Corden, J., Millington, W., Simmonds, P. G., O’Doherty, S., Carslaw, N., and Fuller, G. W.: The origin of high particulate concentrations over the United Kingdom, March 2000, Atmos. Environ., 36, 1363-1378, 2002.

Seinfeld, J. H. and Pandis, S. N.: Atmospheric Chemistry and Physics, From Air Pollution to Climate Change, John Wiley \& Sons, Inc., New York, 1998.

Smirnov, A., Holben, B. N., Dubovik, O., O’Neill, N. T., Eck, F., Westphal, D. L., Goroch, A. K., Pietras, C., and Slutsker, I.: Atmospheric aerosol optical properties in the Persian Gulf, J. Atmos. Sci., 59, 620-634, 2002.

Schwikowski, M., Siebert, P., Baltensperger, U., and Gäggeler, H. W.: A study of an outstanding Saharan dust event at the high-alpine site Jungfraujoch, Switzerland, Atmos. Environ., 29, 1829-1842, 1995.
Sokolik, I. N. and Toon, O. B.: Incorporation of mineralogical composition into models of the radiative properties of mineral aerosol from UV to IR wavelengths, J. Geophys. Res., 104, 9423-9444, 1999.

Stohl, A. , and Trickl, T.: A textbook example of long-range transport: simultaneous observation of ozone maxima of stratospheric and North American origin in the free troposphere over Europe, J. Geophys. Res., 104, 30 445-30 462, 1999.

Takemura, T., Nakajima, T., Dubovik, O., Holben, B. N., and Kinne, S.: Single-scattering albedo and radiative forcing of various aerosol species with a global three-dimensional model, J. Climate, 15, 333-352, 2002.

Wagenbach, D. and Geis, K.: The mineral dust record in a high altitude alpine glacier (Colle Gnifetti, Swiss Alps), in: Paleoclimatology and Paleometeorology: Modern and Past Patterns of Global Atmospheric Transport, edited by: Leinen, M. and Sarnthein, M., 543-564, 1989.

Weingartner, E., Saathof, H., Schnaiter, M., Streit, N., Bitnar, B., and Baltensperger, U.: Absorption of light by soot particles: Determination of the absorption coefficient by means of Aethalometers, J. Aerosol Sci., 34, 1445-1463, 2003.

Weingartner, E., Henning, S., Gysel, M., Bukowiecki, N., and Baltensperger, U.: Hygroscopicity of aerosol particles at low temperatures, J. Aerosol Sci., 32, Suppl. 1, S977-S978, 2001.

Weingartner, E., Nyeki, S., and Baltensperger, U.: Seasonnal and diurnal variation of the aerosol size distribution $(10<D<750 \mathrm{~nm})$ at a high alpine site (Jungfraujoch $3580 \mathrm{~m}$ asl), J. Geophys. Res., 104, 26 809-26 820, 1999.

Wernli, H. and Davies, H. C.: A Lagrangian-based analysis of extratropical cyclones. 1. The method and some applications, Quarterly Journal of the Royal Meteorological Society, 123(538), 467-489, 1997. 